$A L, 2,2002-233$

c. 2

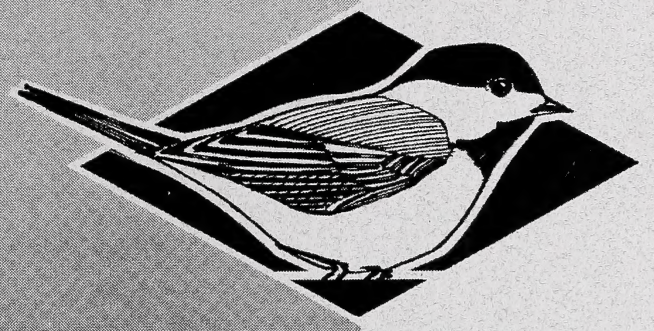

Fish \& Wilolite Division

RESOURCE STATUS AND ASSESSMENT BRANCH

\title{
Protocol for Monitoring Long-toed Salamander (Ambystoma macrodactylum) Populations in Alberta
}

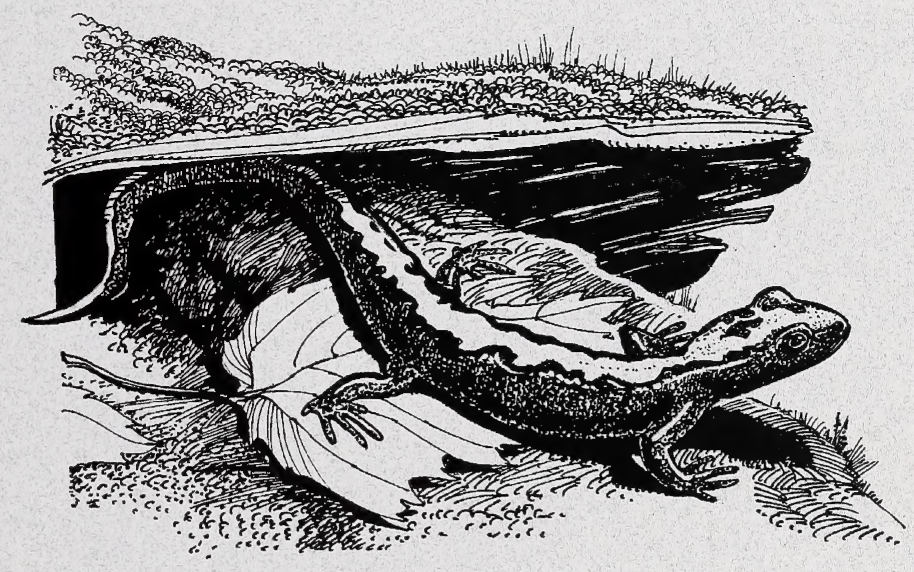

Alberta Species at Risk Report No. 35 
Digitized by the Internet Archive in 2016 


\title{
Protocol for Monitoring Long-toed Salamander (Ambystoma macrodactylum) Populations in Alberta
}

\author{
Troy Pretzlaw \\ Mai-Linh Huynh \\ Lisa Takats \\ and \\ Lisa Wilkinson
}

Alberta Species at Risk Report No. 35

January 2002

Project Partners:
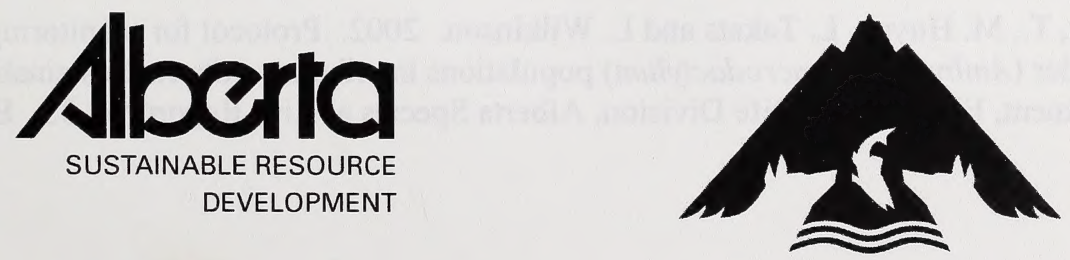

Alberta Conservation Association 
Publication No.: I/052

ISBN: 0-7785-2000-5 (Printed Edition)

ISBN: 0-7785-2001-3 (On-line Edition)

ISSN: 1496-7219 (Printed Edition)

ISSN: 1496-7146 (On-line Edition)

Illustration: Brian Huffman

For copies of this report, contact:

Information Centre - Publications

Alberta Environment / Alberta Sustainable Resource Development

Main Floor, Great West Life Building

9920108 Street

Edmonton, Alberta, Canada T5K 2M4

Telephone: (780) 422-2079

\section{OR}

Information Service

Alberta Environment / Alberta Sustainable Resource Development \#100, 311512 Street NE

Calgary, Alberta, Canada T2E 7J2

Telephone: (403) 297-3362

\section{OR}

Visit our web site at:

http://www3.gov.ab.ca/srd/fw/riskspecies/

This publication may be cited as:

Pretzlaw, T., M. Huynh, L. Takats and L. Wilkinson. 2002. Protocol for monitoring long-toed salamander (Ambystoma macrodactylum) populations in Alberta. Alberta Sustainable Resource Development, Fish and Wildlife Division, Alberta Species at Risk Report No. 35. Edmonton, AB. 
TABLE OF CONTENTS

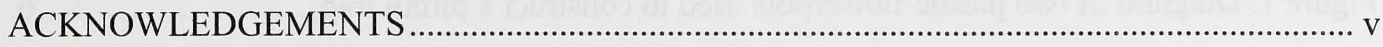

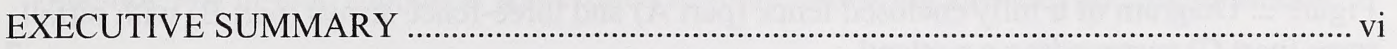

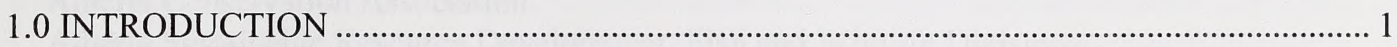

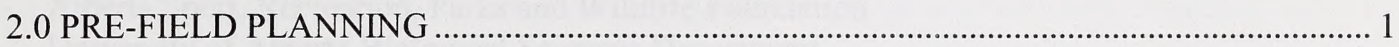

3.0 EGG, LARVAE AND YOUNG-OF-YEAR SURVEY TECHNIQUES ……........................ 2

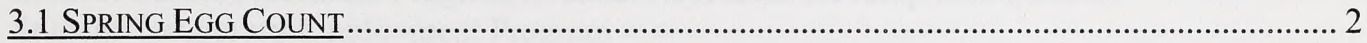

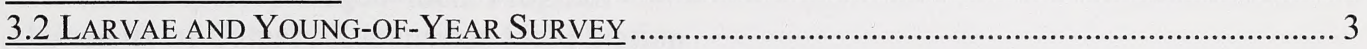

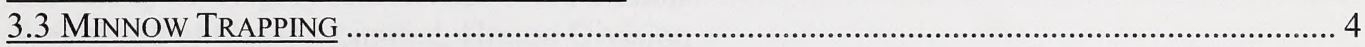

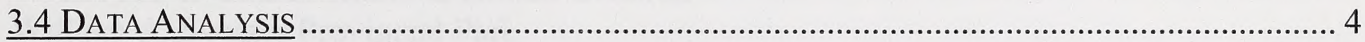

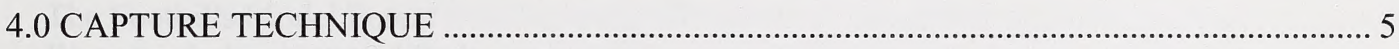

4.1 TRAPPING

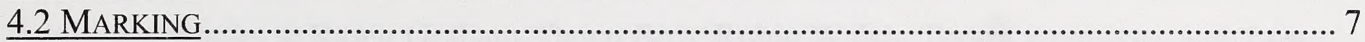

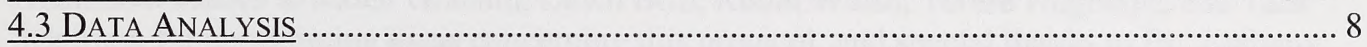

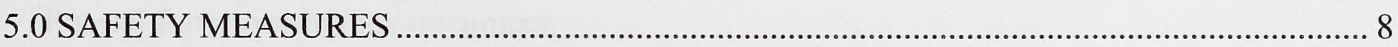

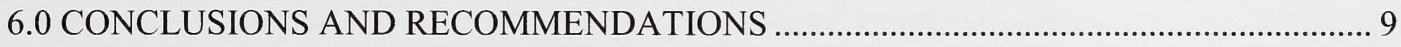

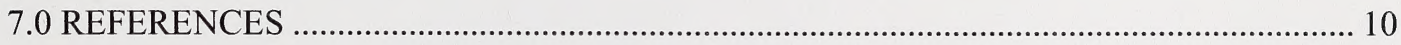

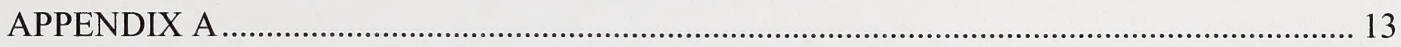




\section{LIST OF FIGURES}

Figure 1. Diagram of two plastic flowerpots used to construct a pitfall trap..................6

Figure 2. Diagram of a fully enclosed fence (part A) and three-fence arrays (part B) with pitfall

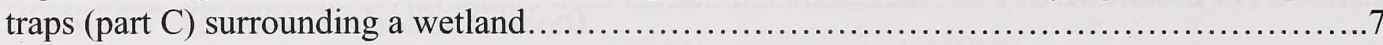




\section{ACKNOWLEDGEMENTS}

Funding and in-kind support is appreciated from the following agencies and organisations:

Alberta Conservation Association

Alberta Sustainable Resource Development, Fish and Wildlife Division

Alberta Sport, Recreation, Parks and Wildlife Foundation

University of Alberta Biological Sciences Department

Canada Trust Friends of the Environment Fund

Student Career Placement Program (Human Resources Development Canada)

Student Temporary Employment Program

University of Calgary Kananaskis Field Station

Weldwood of Canada Limited, Hinton Division

William A. Switzer Provincial Park

The Foothills Model Forest

Waterton Lakes National Park

Additional thanks to Karen Graham, Dawn Birn, Robin Walsh, Teresa Augustyn, and Tara Szkorupa for contributing ideas concerning this protocol, and special thanks to Dr. Anthony Russell for reviewing the document. 


\section{EXECUTIVE SUMMARY}

This document is intended as a guide for studying long-toed salamanders, with emphasis on survey techniques and long-term monitoring. We recommend egg surveys as the best method by which to identify salamander presence, unless water turbidity limits visibility. Egg surveys can also be used as an indirect way to track population trends over time. Larvae searches can be used as an ancillary method to search for presence, but tend to be less reliable because larvae are mobile and cryptic.

Capture methods include pitfall and minnow trapping, the former of which is recommended at permanent sampling sites. Minnow trapping is useful for capturing breeding adults and larvae in ponds where water turbidity prevents egg identification. Capturing adults is useful for gathering data on body parameters and general health, and is considered secondary to pond surveys. Markrecapture is the only method by which to gather data on population size or relative abundance, although it is a long-term, time-consuming process that is confounded by the stochasticity inherent in amphibian populations.

Long-term monitoring of known breeding ponds is necessary to understand population trends and potential risks to populations. A combination of monitoring a subsample of ponds on an annual basis, and surveying all known ponds at five year intervals is recommended for the Alberta program. Surveying new ponds and commencing mark-recapture at an established longterm monitoring site is recommended. 


\subsection{INTRODUCTION}

Long-toed salamanders (Ambystoma macrodactylum) are ranked "sensitive" in Alberta because of their limited breeding range, isolated populations, and vulnerability to habitat change (Graham and Powell 1999). There is, however, a lack of data on population size, distribution, and trends. To obtain these baseline data, a standard approach for studying long-toed salamanders is necessary. This protocol summarizes a combination of techniques to identify presence, index relative abundance, and track population trends over time while minimizing cost and ecological disturbance. This protocol is designed as a step by step approach to surveying and monitoring long-toed salamanders, outlining the applicability of each technique, with specific reference to current monitoring programs and known breeding sites in Alberta. While focused on Alberta, this protocol was designed to be comprehensive enough to be adapted and applied to other locations and study objectives.

Long-toed salamanders are difficult to study because adults are forest-dwelling, cryptic, nocturnal, and spend most of their time underground, under logs, rocks and woody debris, and are consequently rarely seen (Russell and Bauer 2000). The best time to observe adults and confirm presence is during breeding season when adults travel to ponds to breed. Long-toed salamander eggs are distinguishable from other amphibian eggs and are typically the best indicator of salamander presence; larvae and adults are mobile and more difficult to see. Understanding population trends is further complicated due to the inherent stochasticity of amphibian populations, and more specifically, the fact that long-toed salamanders may not breed every year (Heyer 1976).

Determining study objectives is the first step towards selecting techniques. The emphasis of Alberta's long-toed salamander program is on monitoring known breeding ponds for presence of salamanders, tracking population trends, and gathering distribution data. The impetus for this work is the need to evaluate status and identify and implement management and conservation strategies.

\subsection{PRE-FIELD PLANNING}

Within each study area, field reconnaissance is required prior to commencing the survey. Detailed maps and aerial photographs of the survey area should be reviewed to locate and determine access to ponds. Land ownership needs to be established to determine whether permission is required as well as to design monitoring and conservation strategies. Selection of wetlands should be based on three primary criteria: 1) the absence of fish, 2) the permanency of the water body, and 3) accessibility and safety for sampling. Long-toed salamanders will breed in ephemeral ponds, but for the purpose of long-term monitoring emphasis should be placed on permanent waterbodies. Similarly, long-toed salamanders are occasionally found in fish bearing ponds, but current evidence suggests that predatory fish are typically a deterrent to salamanders.

Because aquatic habitat characteristics vary with time, they should be recorded and analysed to allow interpretations of year-year and within-year variation. Thus, a general description involving habitat type(s), substrate type, and pond origin (natural or man-made) is required for 
all surveyed long-toed salamander ponds. The type and amount of habitat data collected will vary with study objectives.

\subsection{EGG, LARVAE and YOUNG-OF-YEAR SURVEY TECHNIQUES}

A combination of techniques that include egg, larvae, and young-of-year shoreline searches, is the most effective and inexpensive way to gather distribution data; emphasis on survey technique varies according to specific objectives and location characteristics. Surveys are time-consuming, requiring keen observation and patience. Shoreline searches are not recommended for highly turbid wetlands (ie. Peace River breeding ponds) and would thus require minnow trapping to capture breeding adults in spring, and larvae and young-of-year in summer.

Ideally, egg searches should be conducted soon after spring melt. Long-toed salamanders are known to commence egg laying at temperatures as low as $4{ }^{\circ} \mathrm{C}$, before ponds are completely free of ice (Powell et al. 1993). Larvae searches should be conducted in late spring when eggs have begun to hatch, and young-of-year searches should be conducted in mid- to late summer when metamorphosis has occurred. Metamorphosis typically occurs within the same season the eggs are laid, but at high elevations larvae may overwinter (Russell and Bauer 2000). Timing of reproductive events will vary between and within breeding areas according to local conditions. The following techniques are standard methods for conducting egg, larvae and young-of-year surveys.

\section{$\underline{\text { 3.1 Spring Egg Count }}$}

Egg counts, under suitable conditions, are the recommended survey method. They are the best way to confirm salamander presence and by counting eggs on an annual basis, they are an indirect way to track population trends. They are inexpensive, time efficient, and minimize stress and disturbance on salamanders because no handling is required. However, because monitoring only one life history stage may mask certain aspects of the population, such as recruitment and adult survivorship, it is important to recognize the limitations of egg counts (Mettler 1988). Nevertheless, monitoring eggs can be useful as an early warning sign of possible declines in the breeding population.

Egg counts can be conducted around the entire pond, or subsampled with transects. Surveying the entire pond is recommended for the greatest consistency and reliability. Because pond edges can be heterogeneous, using permanent transects without consideration of habitat heterogeneity has the potential to over or underestimate egg counts. Such variability in egg counts might be a result of differences in vegetation and turbidity, which can influence visibility. Furthermore, it is unknown if salamanders oviposit within the same location every year.

If the wetland is extremely difficult to survey and/or is very large, permanent transects can be used. Habitat should be stratified into representative, homogeneous groups prior to transect set up. Three transects should be randomly placed along the pond edge using a random numbers table within each homogeneous group; the total length of which should equal $30 \%$ of the pond's perimeter. Permanent transects should be clearly marked with flagged survey pins or flagging tape to allow repeated surveys. 
Ponds should be visited at least three times during the egg-laying period in order to obtain the highest egg count; egg-laying period will vary with location. The number of visits and lengths of surveys should be consistent between and within years. Development time of eggs is likely influenced by pond depth, surface area and elevation. Locations of eggs recorded on the first visit should be marked by placing a flagging pin on the shoreline and monitored for development.

When initially searching for long-toed salamander eggs, an experienced researcher should be present to verify identification. It is recommended, but not necessary, to have two people conduct egg counts to increase reliability and maintain continuity when one researcher is absent. Long-toed salamanders usually attach their eggs to thin, wispy vegetation, but eggs are also found attached to submerged trees, fallen leaves, and other detritus along a pond bottom (Corkran and Thoms 1996; Russell and Bauer 2000). Long-toed salamander eggs are laid singly or in small clumps, and as such are distinct from frog eggs. Long-toed salamander eggs are clear and gelatinous, but may become less distinct over time. They can also be confused with invertebrate eggs; ensure that the eggs do not contain green symbiotic algae and are completely clear. Tiger salamander eggs are also laid singly but are brown or grey above and opaque below (Corkran and Thoms 1996). Refer to Corkran and Thoms (1996) for photo identification and complete descriptions of long-toed salamander eggs and larvae.

Salamander eggs should be counted within $2 \mathrm{~m}$ of shore. Environmental conditions, including ambient and water temperature, water turbidity, cloud cover, wind conditions, pond $\mathrm{pH}$, and relative water levels (using a permanent water level marker) should be recorded. However, depending on water turbidity, light conditions, and wind conditions, eggs might not be readily visible. Consequently, poor ambient conditions should be avoided. Time spent surveying should also be recorded and replicated for other consecutive visits. In large ponds, shoreline egg counts could be achieved by using an inflatable boat. It should be noted, however, that surface area surveyed should be taken into account when collecting and analysing data. Mechanical counters are useful for counting large numbers of eggs, and handheld instruments with multi-parameter capability in single probes that can collect water data on $\mathrm{pH}$, temperature, and turbidity simultaneously, are recommended.

In order to minimize observer bias on egg counts, practise counts are recommended prior to surveying. By taking clumps of eggs out of the water or holding them just below the pond surface or in a dish of water, the observer can estimate the number of eggs and then verify the estimate by counting the actual number of eggs. This exercise should be done several times to ensure that the observer is as accurate as possible, thereby reducing observer bias. This exercise may need to be done at different times during egg development because of increasing egg size.

Sample data sheets, modified from data sheets used in the RANA program (Takats 2000), are provided in Appendix A.

\subsection{Larvae and Young-of-Year Survey}

Egg searches are recommended as the primary survey method, although in ponds where water is clear and there is little or no shoreline vegetation, larvae and young-of-year are often readily visible. Because larvae and young-of-year salamanders are very cryptic and difficult to quantify, 
these data should be used primarily to confirm salamander presence. Shoreline searches for larvae and young-of-year should follow similar methods outlined in Section.1. Number of individuals observed, as well as environmental data and time spent surveying should be recorded. A minimum of three visits throughout the summer is recommended.

\subsection{Minnow Trapping}

The use of minnow traps to catch breeding adults and larvae is advisable when egg counts and/or larvae searches are difficult to conduct, usually because of water turbidity. This technique can be used to confirm presence and gather distribution data, and has been used successfully in the Peace River area (Augustyn 2001; Walsh 1998).

Minnow traps are designed to catch small fish for bait but have been effective at catching amphibians (Mushet et al. 1997; Augustyn 2001; R.Walsh, Pers. Comm.). These traps are commercially available or can be hand made to suit the experimental design of the study. It is recommended, however, to use the redesigned minnow trap as used in Mushet et al. (1997). This redesigned trap allows sampling of the entire water column while simultaneously providing oxygen to captured animals. Using this funnel trap can reduce mortality and allows the trap to be left for extended periods of time.

Number of traps used is dependent upon the surface area of the pond, although there are no specific recommendations for number per unit surface area. Two traps per pond were used in Peace River where ponds were small relative to ponds in other study areas (T. Augustyn, Pers. Comm). Consequently, four traps are likely the minimum required for moderately sized salamander ponds. Each trap should be randomly placed using a random numbers table within each habitat type and be permanently marked with flagging for use throughout the sampling season. All ponds should be sampled at least three times throughout the spring to capture breeding adults and during the mid-summer period to capture larvae. If doubts over larvae identification occur, larvae can be reared through metamorphosis.

Traps should be left in the wetland for 24 hours to ensure unbiased sampling of salamanders with diurnal and nocturnal activity patterns (BAWWG 2001). Upon retrieval, contents should be emptied into a white sorting pan, protecting the researcher from biting snakes and invertebrates. It is also recommended to carry a set of pliers to loosen wires of the trap as salamanders occasionally get stuck in the mesh of traps (T. Augustyn, Pers. Comm.).

As of yet, there have been no studies to compare the efficacy of minnow traps versus pitfall traps (Section 4.1) for capturing breeding adults.

Sample data sheets are provided in Appendix A.

\subsection{Data Analysis}

The primary utility of shoreline searches and minnow trapping is to detect presence of salamanders, however, further analysis can be conducted on egg count data depending on study objectives. Number of eggs counted per metre surveyed should be calculated to allow comparisons between ponds as well as between years. The relative egg abundance value can also be classified by habitat type. Suggested statistical analyses include one-way Analysis of 
Variance (ANOVA) to distinguish relative abundance among habitats, and two-way ANOVA to analyse patterns among habitats and sampling years (Scott and Woodward 1994). These statistical tests can be used to detect changes in egg abundance over time and can be used to infer changes in breeding population size.

For entire pond surveys, one-way ANOVA can be used to compare relative abundance values between years. Regression analysis can also be used to graph the percent of total sites occupied by salamanders by year, for which a test of significance from zero can determine if the range is decreasing or increasing (Mossman 1990, unpubl. report ${ }^{1}$ ).

\subsection{CAPTURE TECHNIQUE}

While egg counts provide distribution data and a mechanism to track population trends, the data can be misleading because they do not provide information on recruitment potential or an estimate of population size. By using the drift fence/pitfall method, number of salamanders caught per year can be compared to get an index of population size and act as an ancillary method by which to track population trends. Pitfall traps should be operated in spring when adults are travelling to breeding ponds, and can also be operated in summer when young-of-year are dispersing. It is important to recognize that drawing conclusions from pitfall trap capture rate, as with other methods discussed thus far, is limited in its applicability because it pertains to only one aspect of the life cycle, can be confounded by salamanders not breeding every year, and does not differentiate individuals. A more accurate estimate of population size can be made using mark-recapture, and is discussed in Section 4.2. Capturing adults is also useful for gathering data on length, mass, sex, breeding condition and general health.

All handling, capture, and marking of salamanders requires approval from the Canadian Council for Animal Care.

\subsection{Trapping}

Pit-fall traps, in combination with drift fences, are a reliable and easy way to capture salamanders. In principle, a salamander entering or leaving the pond is intercepted by the fence, which encircles the pond, and will travel parallel to it until it falls into a trap placed along the edge of the fence. This is an effective technique to capture long-toed salamanders because they have limited climbing and jumping ability.

Pitfall traps are generally containers that are flush with the ground. The following are recommended steps in constructing a pitfall trap (Figure 1):

- Duct tape two large 6-inch plastic flowerpots together, open end to open end. Plastic pots are preferred because they will not rust.

- Cut a hole in the top of the upper pot approximately $1 \mathrm{~cm}$ from the edge, leaving a lip. This lip serves to retain the shape of the pot as well as prevent salamanders from climbing out.

\footnotetext{
${ }^{1}$ Available from Micheal J. Mossman, State of $w$ isconsin, Department of Natural Resources, Southern District Headquaters, 3911 Fish Hatchery Road, Fitchburg, WI 53711-5397, USA.
} 
- Tape shut the drain holes in the lower pot to ensure that trap water level is constant.

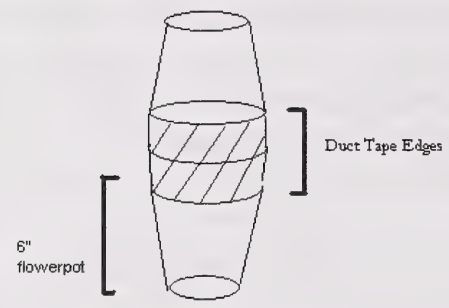

Figure 1. Diagram of two plastic flowerpots used to construct a pitfall trap.

In order to minimize stress on salamanders and accidentally trapped small mammals, the following should be added to the pitfall trap (Figure 2, part C):

- A sponge or moss soaked daily in pond water to prevent desiccation.

- A rock to provide a hiding place and perch for salamanders.

- A stick to allow small mammals to escape.

- A plastic cover supported by stakes should be placed above each trap to protect salamanders from direct sunlight, which can cause overheating and desiccation. The cover will also prevent flooding of the traps during heavy rainfall.

Traps should be checked each morning to minimize mortality from desiccation and predation; if necessary, traps can be left for two days if procedures to ensure moisture and general protection are followed (K.Graham, Pers. Comm.). When traps are not in use, secure a lid on top of each trap. In addition, continual maintenance of the fence and traps is required to prevent salamanders from escaping.

Each captured salamander should be sexed ${ }^{2}$, measured from snout to vent, and weighed. Salamanders can be placed in a moist Ziploc bag for weighing and measuring. By clipping the bag to a clipboard and gently moving the bag towards the clip, the salamander can be held still in a straight position, facilitating measuring body length. A clear plastic or glass tube can also be used for this purpose (R.Walsh, Pers. Comm.). Deformities and other relevant observations should also be recorded. Latex gloves should be worn to prevent spread of infectious agents to salamanders. Captured salamanders should be released on the opposite side of the fence.

For the construction of the drift fence, silt fencing is recommended over polyethylene because of its flexibility and resistance to tearing. The fencing comes in rolls with wooden stakes attached. Fencing and pitfall traps should be installed as follows (Figure 2, part A and B):

\footnotetext{
${ }^{2}$ Males have well-developed fins on the upper and lower edges of the tail and swollen clocae during breeding; females lack tail fins and have smaller cone-shaped cloacae and, when gravid, are much broader in girth than males (Verrell and Pelton 1996).
} 
- Pound fence stakes in rows parallel to the wetland, in such a way as to keep the fence taut. Fences should be placed above the high-water mark.

- Dig a trench to bury silt fences between stakes. The fence should be buried to a depth of 10 $\mathrm{cm}$ to prevent salamanders from burrowing underneath. In rocky terrain, pegs are recommended to secure fencing.

- Bury pitfall traps along the fence, making sure that the tops of the traps are flush with the soil surface.

- For a fully enclosed fence, traps should be placed every $10 \mathrm{~m}$ on both sides of the fence (standard spacing; Rice 2000, Graham 1999).

If the wetland is too large to install a fully enclosed fence, three-fence arrays $(\sim 5 \mathrm{~m}$ long $)$ are recommended and should be placed in the path of salamander migration routes (Fukumoto and Herrero 1998; Rice 2000). If migration routes are unknown, arrays should be randomly placed within each habitat type around the pond (Scott and Woodward 1994). Depending on pond size, between two and five arrays per habitat type within $500 \mathrm{~m}$ of the shore are recommended. However, a fully enclosed pond is preferable.

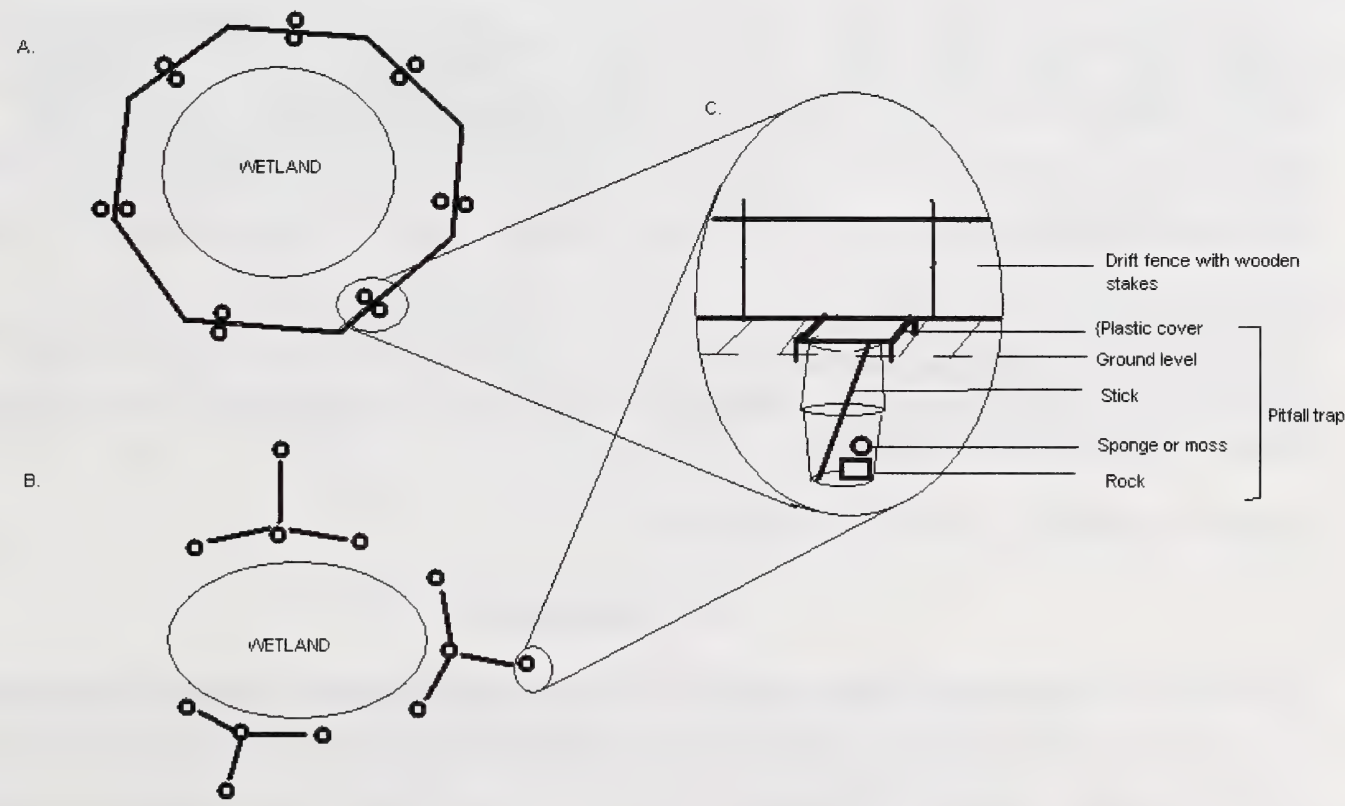

Figure 2. Diagram of a fully enclosed fence (part A) and three-fence arrays (part B) with pitfall traps (part C) surrounding a wetland.

\subsection{Marking}

Marking individuals is crucial in estimating abundance; without marking, recapture rates are unknown, making relative abundance values difficult to interpret (Dodd and Scott 1994). Furthermore, it is imperative to conduct mark-recapture for several years because salamanders 
may not breed every year (Heyer 1976), or may use a different wetland of close proximity (Amphibian Survey Protocol 1999). Mark-recapture can also provide data on survivorship and other population parameters.

A limited number of marking techniques exist, of which Visible Implant Florescent Elastomer (VIE) is the least obtrusive to salamanders and most effective (Mallory 1998; Binckley et al. 1998; Anholt et al. 1998; Wendlandt and Takats 2000). Animals are tagged by injecting a small amount of a non-toxic latex under the surface of the skin. Toe clipping is not viable for longterm studies because of toe regeneration. In contrast, VIE has been observed to last for the entire life span of the salamander (Northwest Marine Technology 2000).

VIE kits, which include injection and handling instructions, are available from Northwest Marine Technology (2000). Elastomer tags come in two parts, a coloured elastomer and a curing kit, which are mixed in a 10:1 ratio on site. Handheld $0.3 \mathrm{cc}$ syringes are used to inject the elastomer mixture just under the skin. The resulting tag is visible with the naked eye and can be optically enhanced with a portable blue LED light. By using four different florescent dyes and four different tagging locations, individual salamanders can be uniquely marked. Depending on study objectives, marking breeding cohorts may be sufficient.

To minimize any possible negative side effects of this technique, tags should be injected on the ventral surface of the salamanders' legs (Blinkley et al. 1998). Blinkley et al. (1998) also suggest placing salamanders in a wet Ziploc bag that is then clipped to a clipboard. This prevents salamanders from desiccating and makes the injection process easier by having the salamander pinned between the end of the bag and the clip. Possible errors in the injection process and injury to the salamander are reduced using this method. Syringes should be sterilised between each use.

Marking salamanders should be conducted daily for the duration of the trapping period (spring for breeding adults and late summer for emerging young-of-year). Mark-recapture should continue a minimum of three years, although five years is recommended due to the stochasticity inherent in amphibian populations.

Sample data sheets are provided in Appendix A.

\subsection{Data Analysis}

The number of salamanders caught should be divided into the number of trap nights (excluding the number recaptures within the same trapping season) in order to obtain a standard relative abundance value. One-way ANOVA can then be used to compare these values between sampling years. Population estimates and changes over time can be calculated from mark-recapture data using various software programs.

\subsection{SAFETY MEASURES}

For safety reasons it is recommended that two surveyors work together. Surveyors are encouraged to have a daily check-in with whom they should leave their daily itinerary, including pond locations and time expected back. Surveyors should also carry cell phones or radios when 
working alone. Hazards of working in wetlands include unwadable shores, floating edges, softorganic bottoms, filling waders with water, exposure to cold conditions, wildlife (bears, cougars, etc.) and people (Amphibian Survey Protocol 1999). It is advisable for the surveyors to be familiar with bear safety, first aid, and general safe operating procedures. The local Conservation Officer and other relevant individuals should be contacted prior to commencing field work.

\subsection{CONCLUSIONS AND RECOMMENDATIONS}

Currently, Alberta's long-toed salamander program is focused on continued monitoring of known breeding areas by verifying presence of salamanders (typically through egg searches). A subsample of known breeding ponds should be monitored annually for a minimum of five years, and a complete inventory should be conducted every five years. Counting eggs is an indirect method by which to track population trends and is recommended at long-term monitoring sites. Surveying new ponds during egg-laying season is also important to get a complete understanding of salamander distribution, particularly in recently identified breeding areas (ie. Peace River). Mark-recapture is not recommended for all monitoring sites and should only be used when necessary to achieve specific study objectives. This method is time consuming, long-term, and can be confounded by various factors associated with the stochastic nature of amphibian populations. However, mark-recapture is recommended at one long-term monitoring site as a representative site for collecting data on population size and demographics.Finally, education and conservation should be incorporated into monitoring programs. 


\subsection{REFERENCES}

Alberta endangered Species Conservation Committee. 2000. First report of the Alberta Endangered Species Conservation Committee. Alberta Environment, Fisheries and Wildlife Management Division. 24 pp.

Amphibian Survey Protocol. 1999. King County Water and Land Resources Volunteer Amphibian Monitoring Program. http://students.washington.edu/kchall/frinkpark/work docs/Amphibian protocols.doc.htm.

Anholt, B., S. Negovetic, C. Som, and R. Mulheim. 1998. Marking tadpoles with VIE. http://www.mpl-pwrc.usgs.gov/marking/anholt.html.

Augustyn, T. 2001. Long-toed salamander (Ambystoma macrodactylum) Monitoring in the Peace Region of Alberta. Report prepared for Alberta Sustainable Resource Development, Fish and Wildlife Division, Grande Prairie, AB.

Binckley, C. A., B. Plesky, K. Werner, and S. Droege. 1998. Using the visible implant fluorescent elastomer to mark Plethodon cinereus. http://www.mplpwrc.usgs.gov/marking/pwrc.html.

Biological Assessment of Wetlands Workgroup (BAWWG). 2001. Environmental Protection Agency. www.epa.gov/owow/wetlands/bawwg/.

Corkran, C. and C. Thoms. 1996. Amphibians of Oregon, Washington and British Columbia. Lone Pine Publishing, Canada.

Dodd,C.K. and D.E. Scott. 1994. In Heyer, W.R., M.A. Donnelly, R.W. McDiarmid, L.C. Hayek and M.S. Foster (eds), Measuring and Monitoring Biological Diversity: Standard Methods of Amphibians. Smithsonian Institution Press, Washington.

Fukumoto, J. and S. Herrero. 1998. Observations of the Long-toed salamander, Ambystoma macrodactylum, in Waterton National Park, Alberta. The Canadian Field-Naturalist 112(4):579-585.

Graham, K. L. 1997. Habitat use by long-toed salamanders (Ambystoma macrodactylum) at three different scales. M. Sc. Thesis, University of Guelph, Guelph, ON.

Graham, K. L., and G. L. Powell. 1999. Status of the long-toed salamander (Ambystoma macrodactylum) in Alberta. Alberta Environmental Protection, Fisheries and Wildlife Management Division, and Alberta Conservation Association, Wildlife Status Report No. 22, Edmonton, $\mathrm{AB}$.

Heyer, W.R. 1976. Studies in larvae amphibian habitat partitioning. Smithsonian Contrib. Zool. 242:1-27. 
Huynh, M.L. 2001. Hinton Final Report 2001. In Takats, L. Unpubl. report. RANA, researching amphibian numbers in Alberta, Final Report for 2001. Alberta Conservation Association. Edmonton, Alberta.

Mallory, K. 1998. Fluorescent elastomer marking of larvae salamanders. http://www.mplpwrc.usgs.gov/marking/mallory.html.

Mettler, L. 1988. Lower Snake River Juvenile Salmon Migration Feasibility Study: Distribution and Abundance of Amphibians and Reptiles in Riparian and Upland Habitatis Along the Lower Snake River. Part I0 Field Studies, Methods- Sampling Methods. www.nww. usace.army.mil/html/offices/pl/er/studies/lsrpublic/reports/reptiles/sample.htm.

Mushet, D.M., N.H. Eulliss, B.H. Hanson, and S.G. Zodrow. 1997. A funnel trap for sampling salamanders in wetlands. Herpetological Review 28 (3) 132-133. Northern Prairie Wildlife Research Center Home Page. http://www.npwrc.usgs.gov/resource/tools/ funnel/funnel.htm (Version 02FEB98).

Northwest Marine Technology. 2000. Northwest Marine Technology, Inc. Visible Implant fluorescent Elastomer (VIE) Product Information. http://www.nmt-inc.com/Products/ VIE/vie.html.

Paton, D. 2002. Columbian mountain amphibian surveys, 2001. Alberta Sustainable Resource Development, Fish and Wildlife Division, Alberta Species at Risk Report No. 39. Edmonton, Alberta.

Powell, G.Ll., S.J. Nelson, and A.P. Russell. 1993. The Bow Valley Long-toed salamander population study: a preliminary report on the 1992 field season. Alberta Environmental Protection, Fish and Wildlife Service, Edmonton Alberta. 124pp.

Rice, C. 2000. Pilot monitoring plan for long-toed salamanders (Ambystoma macrodactylum) in Alberta. Alberta Environment, Edmonton, Alberta.

Russell, A.P. and A.M. Bauer. 2000. The amphibians and reptiles of Alberta. University of Calgary Press, Calgary, Alberta.

Scott, N.J. and B.D. Woodward. 1994. In Heyer, W.R., M.A. Donnelly, R.W. McDiarmid, L.C. Hayek and M.S. Foster (eds), Measuring and Monitoring Biological Diversity: Standard Methods of Amphibians. Smithsonian Institution Press, Washington.

Takats, L. 2000. RANA, researching amphibian numbers in Alberta, 1999-2000 final report. Alberta Conservation Association, Edmonton, Alberta.

Verrell, P. and J. Pelton. 1996. The sexual strategy of the central long-toed salamander, Ambystoma macrodactylum columbianum, in south-eastern Washington. Journal of Zoology 204: 37-50.

Walsh, R. 1998. An extension of the known range of the Long-toed salamander, Ambystoma macrodactylum, in Alberta. Canadian Field-Naturalist 112(6):331-333. 
Wendlandt, M., and L. Takats. 2000. Northern leopard frog reintroduction, Raven River - pilot year 1999. Alberta Conservation Association and Alberta Environment, Edmonton, Alberta. 
APPENDIX A

\section{Data Sheets}




\section{Long-toed salamander Mark-Recapture Data Sheet}

\section{Survey Information}

\begin{tabular}{|l|l|l|}
\hline Surveyor (s) & Date $(\mathrm{m} / \mathrm{d} / \mathrm{y})$ \\
\hline Site name & & \\
\hline
\end{tabular}

\section{Weather Data}

\begin{tabular}{|l|l|l|l|}
\hline Air temperature $\left({ }^{\circ} \mathrm{C}\right)$ & \multicolumn{2}{|c|}{ Cloud cover $(\%)$} & \\
\hline Wind & 0 still - smoke rises vertically & 4 moderate breeze - thin branches move \\
(Beaufort scale) & 1 light air - smoke drifts & 5 fresh breeze - small trees sway \\
& 2 light breeze - leaves rustle & 6 strong breeze - large branches move \\
& 3 gentle breeze - leaves and twigs & 7 moderate gale - large trees sway \\
& move & \\
\hline Precipitation & 0 None $\quad$ 1 drizzle 2 light rain & 3 medium rain & 4 heavy rain \\
\hline
\end{tabular}

\section{Water Data}

\begin{tabular}{|l|l|l|}
\hline Water temperature $\left({ }^{\circ} \mathrm{C} @ 1 \mathrm{~m}\right)$ & Water $\mathrm{pH}$ & Water Depth/ Snow Depth (cm) \\
\hline
\end{tabular}

\begin{tabular}{|c|c|c|c|c|c|c|}
\hline \multirow{3}{*}{ Array } & \multirow{3}{*}{$\operatorname{Trap}^{2}$} & \multirow{3}{*}{$\begin{array}{c}\mathrm{SVL}^{3}(\mathrm{~cm}) / \\
\operatorname{Sex}(\mathrm{m} / \mathrm{f})\end{array}$} & \multirow{3}{*}{ Weight (g) } & lamande & & \\
\hline & & & & \multicolumn{2}{|c|}{ VIE $^{4}$ tag colour (front legs) } & \multirow[t]{2}{*}{ Notes (abnormalities etc.) } \\
\hline & & & & Left & Right & \\
\hline & & & & & & \\
\hline & & & & & & \\
\hline & & & & & & \\
\hline & & & & & & \\
\hline & & & & & & \\
\hline & & & & & & \\
\hline & & & & & & \\
\hline & & & & & & \\
\hline & & & & & & \\
\hline & & & & & & \\
\hline & & & & & & \\
\hline & & & & & & \\
\hline & & & & & & \\
\hline
\end{tabular}

Footnotes:

1- Array Number

2- "I" for inside trap, or "O" for outside trap (Trap closest to the pond and Trap farthest from the pond respectively)

3- $\quad \mathrm{SVL}=$ Snout-to-Vent Length

4- VIE=Visible Implant fluorescent Elastomer 
Salamander Data

\begin{tabular}{|c|c|c|c|c|c|c|}
\hline \multirow[t]{2}{*}{ Array ${ }^{1}$} & \multirow[t]{2}{*}{ Trap $^{2}$} & \multirow{2}{*}{$\begin{array}{c}\mathrm{SVL}^{3}(\mathrm{~cm}) / \\
\operatorname{Sex}(\mathrm{m} / \mathrm{f})\end{array}$} & \multirow[t]{2}{*}{ Weight (g) } & \multicolumn{2}{|c|}{$\mathrm{VIE}^{4}$ tag colour (front legs) } & \multirow[t]{2}{*}{ Notes (abnormalities etc.) } \\
\hline & & & & Left & Right & \\
\hline & & & & & & \\
\hline & & & & & & \\
\hline & & & & & & \\
\hline & & & & & & \\
\hline & & & & & & \\
\hline & & & & & & \\
\hline & & & & & & \\
\hline & & & & & & \\
\hline & & & & & & \\
\hline & & & & & & \\
\hline & & & & & & \\
\hline & & & & & & \\
\hline & & & & & & \\
\hline & & & & & & \\
\hline & & & & & & \\
\hline & & & & & & \\
\hline & & & & & & \\
\hline & & & & & & \\
\hline & & & & & & \\
\hline & & & & & & \\
\hline & & & & & & \\
\hline & & & & & & \\
\hline & & & & & & \\
\hline & & & & & & \\
\hline & & & & & & \\
\hline & & & & & & \\
\hline & & & & & & \\
\hline
\end{tabular}

Footnotes:

1- Array Number

2- "I" for inside trap, or "O" for outside trap (Trap closest to the pond and Trap farthest from the pond respectively)

3- $\quad$ SVL $=$ Snout-to-Vent Length

4- VIE=Visible Implant fluorescent Elastomer 


\section{Long-toed salamander Minnow Trap Data Sheet}

\section{Survey Information}

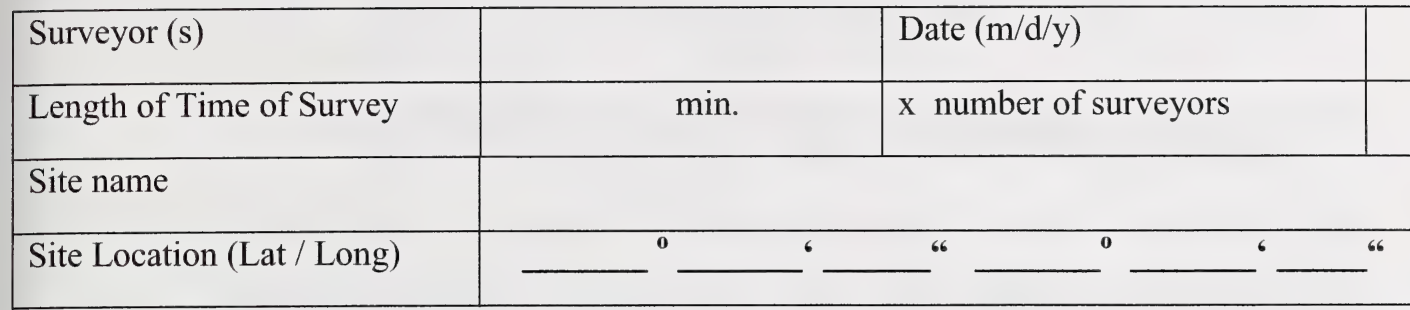

\section{Weather Data}

\begin{tabular}{|l|l|l|l|}
\hline Air temperature $\left({ }^{\circ} \mathrm{C}\right)$ & \multicolumn{2}{|c|}{ Cloud cover $(\%)$} & \\
\hline Wind & 0 still - smoke rises vertically & 4 moderate breeze - thin branches \\
(Beaufort scale) & 1 light air - smoke drifts & move \\
& 2 light breeze - leaves rustle & 5 fresh breeze - small trees sway \\
& 3 gentle breeze - leaves and twigs & 6 strong breeze - large branches move \\
& move & 7 moderate gale - large trees sway \\
\hline Precipitation & 0 None 1 drizzle 2 light rain & 3 medium rain & 4 heavy rain \\
\hline
\end{tabular}

Water Data

\begin{tabular}{|l|l|l} 
Water temperature $\left({ }^{\circ} \mathrm{C} @ 1 \mathrm{~m}\right)$ & Water $\mathrm{pH}$ & Water Depth/ Snow Depth $(\mathrm{cm})$
\end{tabular}

\begin{tabular}{|c|c|c|c|}
\hline & \multicolumn{3}{|c|}{ Minnow Trap Data } \\
\hline Trap & $\begin{array}{l}\text { No. of Salamanders or } \\
\text { Larvae }\end{array}$ & $\begin{array}{l}\text { VIE tag } \\
\text { ID }\end{array}$ & Notes (i.e. habitat type, number of recaptures) \\
\hline 1 & & & \\
\hline 2 & & & \\
\hline 3 & & & \\
\hline 4 & & & \\
\hline $\begin{array}{l}5 \text { (for } \\
\text { exceptional } \\
\text { ly large } \\
\text { ponds) }\end{array}$ & & & \\
\hline
\end{tabular}

Adult Salamander Attribute Data

\begin{tabular}{|c|c|c|c|c|c|c|}
\hline \multirow[t]{2}{*}{ Array } & \multirow{2}{*}{$\begin{array}{c}\text { Trap } \\
\text { Number }\end{array}$} & \multirow{2}{*}{$\begin{array}{l}\operatorname{SVL}(\mathrm{cm}) / \\
\operatorname{Sex}(\mathrm{m} / \mathrm{f})\end{array}$} & \multirow[t]{2}{*}{ Weight $(\mathrm{g})$} & \multicolumn{2}{|c|}{ VIE tag colour (front legs) } & \multirow[t]{2}{*}{ Notes (abnormalities etc.) } \\
\hline & & & & Left & Right & \\
\hline & & & & & & \\
\hline & & & & & & \\
\hline & & & & & & \\
\hline & & & & & & \\
\hline
\end{tabular}




\section{List of Titles in This Series}

(as of January 2002)

No. 1 Alberta species at risk program and projects 2000-2001, by Alberta Sustainable Resource Development, Fish and Wildlife Division. (2001)

No. 2 Survey of the peregrine falcon (Falco peregrinus anatum) in Alberta, by R. Corrigan. (2001)

No. 3 Distribution and relative abundance of the shortjaw cisco (Coregonus zenithicus) in Alberta, by M. Steinhilber and L. Rhude. (2001)

No. 4 Survey of the bats of central and northwestern Alberta, by M.J. Vonhof and D. Hobson. (2001)

No. 52000 survey of the Trumpeter Swan (Cygnus buccinator) in Alberta, by M.L. James and A. James. (2001)

No. 6 2000/2001 Brassy Minnow inventory at Musreau Lake and outlet, by T. Ripley. (2001)

No. 7 Colonial nesting waterbird survey in the Northwest Boreal Region -2000 , by M. Hanneman and M. Heckbert. (2001)

No. 8 Burrowing owl trend block survey and monitoring - Brooks and Hanna areas, by D. Scobie and R. Russell. (2000)

No. 9 Survey of the Lake Sturgeon (Acipenser fulvescens) fishery on the South Saskatchewan River, Alberta (June-September, 2000), by L.A. Winkel. (2000)

No. 10 An evaluation of grizzly bear-human conflict in the Northwest Boreal Region of Alberta (19912000 ) and potential mitigation, by T. Augustyn. (2001)

No. 11 Harlequin duck monitoring in the Northern East Slopes of Alberta: 1998-2000 preliminary results, by J. Kneteman and A. Hubbs. (2000)

No. 12 Distribution of selected small mammals in Alberta, by L. Engley and M. Norton. (2001)

No. 13 Northern leopard frog reintroduction. Raven River - Year 2 (2000), by K. Kendell. (2001)

No. 14 Cumulative effects of watershed disturbances on fish communities in the Kakwa and Simonette watersheds. The Northern Watershed Project. Study 3 Progress report, by T. Thera and A. Wildeman. (2001)

No. 15 Harlequin duck research in Kananaskis Country in 2000, by C.M. Smith. (2001)

No. 16 Proposed monitoring plan for harlequin ducks in the Bow Region of Alberta, by C.M. Smith. (2001)

No. 17 Distribution and relative abundance of small mammals of the western plains of Alberta as determined from great horned owl pellets, by D. Schowalter. (2001)

No. 18 Western blue flag (Iris missouriensis) in Alberta: a census of naturally occurring populations for 2000 , by R. Ernst. (2000)

No. 19 Assessing chick survival of sage grouse in Canada, by C.L. Aldridge. (2000)

No. 20 Harlequin duck surveys of the Oldman River Basin in 2000, by D. Paton. (2000) 
No. 21 Proposed protocols for inventories of rare plants of the Grassland Natural Region, by C. Wallis. (2001)

No. 22 Utilization of airphoto interpretation to locate prairie rattlesnake (Crotalus viridis viridis) hibernacula in the South Saskatchewan River valley, by J. Nicholson and S. Rose. (2001)

No. 23 2000/2001 Progress report on caribou research in west central Alberta, by T. Szkorupa. (2001)

No. 24 Census of swift fox (Vulpes velox) in Canada and Northern Montana: 2000-2001, by A. Moehrenschlager and C. Moehrenschlager. (2001)

No. 25 Population estimate and habitat associations of the long-billed curlew in Alberta, by E.J. Saunders. (2001)

No. 26 Aerial reconnaissance for piping plover habitat in east-central Alberta, May 2001, by D.R.C. Prescott. (2001)

No. 27 The 2001 international piping plover census in Alberta, by D.R.C. Prescott. (2001)

No. 28 Prairie rattlesnake (Crotalus viridis viridis) monitoring in Alberta - preliminary investigations (2000), by S.L. Rose (2001)

No. 29 A survey of short-horned lizard (Phrynosoma hernandesi hernandesi) populations in Alberta, by J. James (2001)

No. 30 Red-sided garter snake (Thamnophis sirtalis parietalis) education and relocation project - final report, by L. Takats (2002)

No. 31 Alberta furbearer harvest data analysis, by K.G. Poole and G. Mowat (2001)

No. 32 Measuring wolverine distribution and abundance in Alberta, by G. Mowat (2001)

No. 33 Woodland caribou (Rangifer tarandus caribou) habitat classification in northeastern Alberta using remote sensing, by G.A. Sanchez-Azofeifa and R. Bechtel (2001)

No. 34 Peregrine falcon surveys and monitoring in the Parkland Region of Alberta, 2001, by R. Corrigan (2002)

No. 35 Protocol for monitoring long-toed salamander (Ambystoma macrodactylum) populations in Alberta, by T. Pretzlaw, M.-L. Huynh, L. Takats and L. Wilkinson (2002) 




National Library of Canada
Bibliothèque nationale du Canada Bibliothèque nationale du Canada 